\title{
Analysis of shallow failures triggered by the 14-16 November 2002 event in the Albaredo valley, Valtellina (Northern Italy)
}

\author{
S. Dapporto ${ }^{1}$, P. Aleotti ${ }^{2}$, N. Casagli ${ }^{1}$, and G. Polloni ${ }^{2}$ \\ ${ }^{1}$ Department of Earth Sciences, University of Florence, Italy \\ ${ }^{2}$ ENI-SNAMPROGETTI, Milano, Italy
}

Received: 24 October 2004 - Revised: 9 March 2005 - Accepted: 10 March 2005 - Published: 15 September 2005

\begin{abstract}
On 14-16 November 2002 the North Italy was affected by an intense rainfall event: in the Albaredo valley (Valtellina) more than $200 \mathrm{~mm}$ of rain fell triggering about 50 shallow landslides, mainly soil slips and soil slip-debris flows.

Landslides occurred above the critical rainfall thresholds computed by Cancelli and Nova (1985) and Ceriani et al. (1994) for the Italian Central Alps: in fact the cumulative precipitation at the soil slips initiation time was $230 \mathrm{~mm}$ (in two days) with a peak intensity of $15 \mathrm{~mm} / \mathrm{h}$.

A coupled analysis of seepage and instability mechanisms is performed in order to evaluate the potential for slope failure during the event. Changes in positive and negative pore water pressures during the event are modelled by a finite element analysis of water flow in transient conditions, using as boundary condition for the nodes along the slope surface the recorded rainfall rate. The slope stability analysis is conducted applying the limit equilibrium method, using pore water pressure distributions obtained in the different time steps by the seepage analysis as input data for the calculation of the factor of safety.
\end{abstract}

\section{Introduction}

On 14-16 November 2002 Valtellina was affected by a prolonged intense rainfall: in the middle and lower valley more than $200 \mathrm{~mm}$ fell triggering many geomorphic processes connected both to fluvial and slope dynamics (Aleotti and Polloni, 2003). The recorded landslides were mainly soil slips and debris flows but also large debris slides and deep seated instabilities occurred. In particular in the studied area (Albaredo valley, left tributary of the Valtellina Valley) more than 50 shallow failures were inventoried, mainly involving natural slopes (Fig. 1).

Correspondence to: S. Dapporto

(dapporto@geo.unifi.it)
In order to determine the mechanisms that triggered landslides, field observations were conducted as well as in situ and laboratory tests. A combined hydrological and stability analysis was then carried out, to evaluate the effects of positive and negative pore water pressures changes on slope instability.

\section{Rainfall induced landslides}

During the critical rainfall of the event, defined as the amount of precipitation from the time in which a sharp increase in rainfall intensity is observed and the triggering of the (first) landslide (Aleotti, 2004), the maximum intensities in the Albaredo area were recorded in the afternoon of 16 November with a peak of $14 \mathrm{~mm} / \mathrm{h}$ at 15:00 local time (LT) when the first landslides occurred. The cumulative rain at soil slip initiation time was $230 \mathrm{~mm}$ corresponding to the $18 \%$ of the mean annual precipitation. Statistical analyses of rainfall data show that the return period for this meteoric event spans from 5 years for the $12 \mathrm{~h}$-rainfall up to 100 years for the $60 \mathrm{~h}$ rainfall.

Landslides occurred above the critical thresholds computed by Cancelli and Nova (1985) and Ceriani et al. (1994) for the Valtellina region and inside the "long heavy rainfall" field proposed by Moser and Hohensinn (1983). It is important to note that rainfall intensities higher than those recorded during the events that struck Valtellina on July 1987 and November 2000 were necessary to trigger the landslides, because, unlike these events, the antecedent precipitation was very scarce ( $7 \mathrm{~mm}$ in the previous 15 days).

Landslides were soil slips and soil slip-debris flows affecting the quaternary cover up to a depth of $0.5-1.0 \mathrm{~m}$. Slide breadth (B) and length (L) are usually less than $10 \mathrm{~m}$ and $50 \mathrm{~m}$, respectively, with a prevalent $\mathrm{B} / \mathrm{L}$ ratio from 0.1 to 0.5 . Most failures occurred over slopes inclined from $35^{\circ}$ to $50^{\circ}$ but the maximum frequency is observed in the $40-45^{\circ}$ class. All soil slips involved only grassland areas. 


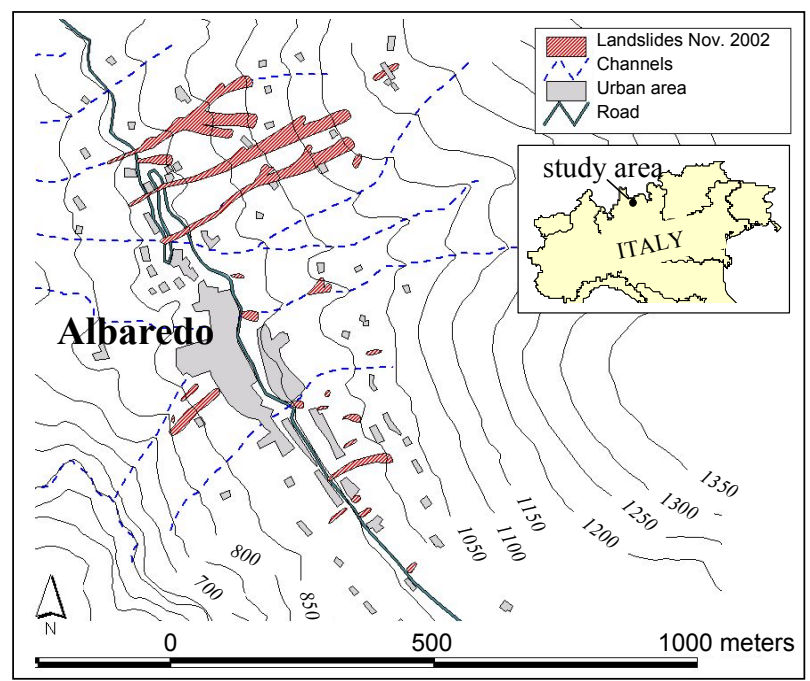

Fig. 1. Landslide map in the Albaredo area.

\section{Geotechnical characterisation}

In situ and laboratory tests allowed to reconstruct the mechanical behaviour of soils involved in the landslides. A representative site in terms of physiographic setting and mechanism of failure was selected for testing activity. The stratigraphy at the landslide source area includes an upper colluvial soil, $1.1 \mathrm{~m}$ thick, subdivided in two levels with different properties (A and B), overlying a $1 \mathrm{~m}$ thick coarse glacial deposit (C), and the bedrock (D) (Fig. 2). Failure surfaces are generally localised into the colluvial layers. Disturbed and undisturbed soil samples were collected at the landslide scars. According to the Unified Soil Classification System (USCS), layers A and B can be classified as silty sand with gravel (SM), with very low clay content (4\% and 5\%, respectively) and a uniformity coefficient greater than 70 . Porosity ranges between $45 \%$ and $48 \%$; dry unit weight varies between $13.8 \mathrm{kN} / \mathrm{m}^{3}$ and $14.3 \mathrm{kN} / \mathrm{m}^{3}$. Soils are not plastic, with a liquid limit of $30 \%$.

Direct shear tests were conducted in remoulded samples with sieved particles finer than $2 \mathrm{~mm}$, to eliminate bigger clasts that could have altered the determinations. The results, in the 30 to $100 \mathrm{kPa}$ stress range, indicate an effective friction angle $\left(\phi^{\prime}\right)$ of $36^{\circ}$ and a negligible effective cohesion $\left(c^{\prime}=0.5 \mathrm{kPa}\right)$.

The Borehole Shear Test (BST) was utilized to evaluate the shear strength parameters directly in situ. Tests were performed on soils under unsaturated conditions, with a mean matric suction of $6.5 \mathrm{kPa}$ as resulted by tensiometric readings at the same depths as the BST tests. The BST provided a linear relationship between the net normal stress and the shear strength in a stress interval ranging from 0 to $80 \mathrm{kPa}$, with $\phi^{\prime}$ values ranging between $35.8^{\circ}$ and $37.5^{\circ}$ and total cohesion (c) values ranging from $2.3 \mathrm{kPa}$ to $8.8 \mathrm{kPa}$.

A Compact Constant Head Permeameter (Amoozegar, 1989) was used to perform in situ measurements of the sat- urated hydraulic conductivity $\left(k_{s}\right)$. Measured values range between $6.6 \mathrm{E}-6 \mathrm{~m} / \mathrm{s}$ and $1.0 \mathrm{E}-5 \mathrm{~m} / \mathrm{s}$ and between $1.5 \mathrm{E}-6 \mathrm{~m} / \mathrm{s}$ and $1.6 \mathrm{E}-6 \mathrm{~m} / \mathrm{s}$ for layers A and B, respectively.

\section{Analysis of slope instability}

\subsection{Modelling scenarios}

In the analyses different scenarios have been considered (Fig. 2), with variable slope length and thickness of the colluvial layers (A and B). This allowed a parametric investigation of the most critical settings for slope stability. The modelled slope is geometrically a planar slope with soil layers parallel to ground surface. The thickness of layers A and B was allowed to vary between $0.5 \mathrm{~m}$ and $2 \mathrm{~m}$ and between $0 \mathrm{~m}$ and $1.5 \mathrm{~m}$, respectively. Layer $\mathrm{C}$, the glacial deposit, is instead included in all the simulations with a constant thickness of $1 \mathrm{~m}$. Each stratigraphical configuration was tested adopting a slope angle $(\beta)$ of $38^{\circ}$ and two different horizontal lengths $(\mathrm{X}): 15 \mathrm{~m}$ and $30 \mathrm{~m}$.

\subsection{Seepage and stability analysis}

Transient saturated and unsaturated flow within the slope was modelled by a 2-D finite element code SEEP/W v.4 (GeoSlope, 1998a). Hydraulic properties of A, B and C soils were derived both from experimental data and from the literature. In particular, porosity and hydraulic conductivity are those obtained by field and laboratory investigations, excepted for the glacial deposit (C) for which values were inferred based on its grain size distribution (Fig. 2). The characteristic curves and the hydraulic conductivity functions were obtained from curves derived from the literature for soils with a similar grain size distribution of the matrix, adjusting the saturated water content $\left(\theta_{S}\right)$ and permeability $\left(k_{s}\right)$ values to the actual measured or assumed values for the three soil types.

Initial conditions were defined assigning a matric suction of $6.5 \mathrm{kPa}$ to the nodes. Regarding the boundary conditions, a transient flux function, with values equal to the rainfall rate of the event was applied to the nodes along the ground surface. A null flux condition was imposed at the lower boundary, therefore excluding any exchange of water between soil $\mathrm{C}$ and the bedrock. A null flux condition was also assigned to the upslope and downslope vertical faces of the model. However, in the latter case the Infinite Elements option has been selected to extend the actual right edge to infinity in the positive $\mathrm{x}$-direction, to avoid an unnatural impermeable border and minimize any side effects. Finally, the simulations were performed dividing the event into 32 time steps of variable length, in order to replicate as closely as possible the variations in rainfall intensities.

Slope stability analyses were conducted for each of the scenarios used for seepage analysis, using pore water pressures determined at different time steps as input data for a limit equilibrium analysis performed with SLOPE/W v.4 (Geo-Slope, 1998b) software. The factor of safety of the colluvial cover (A and B) was computed with the 


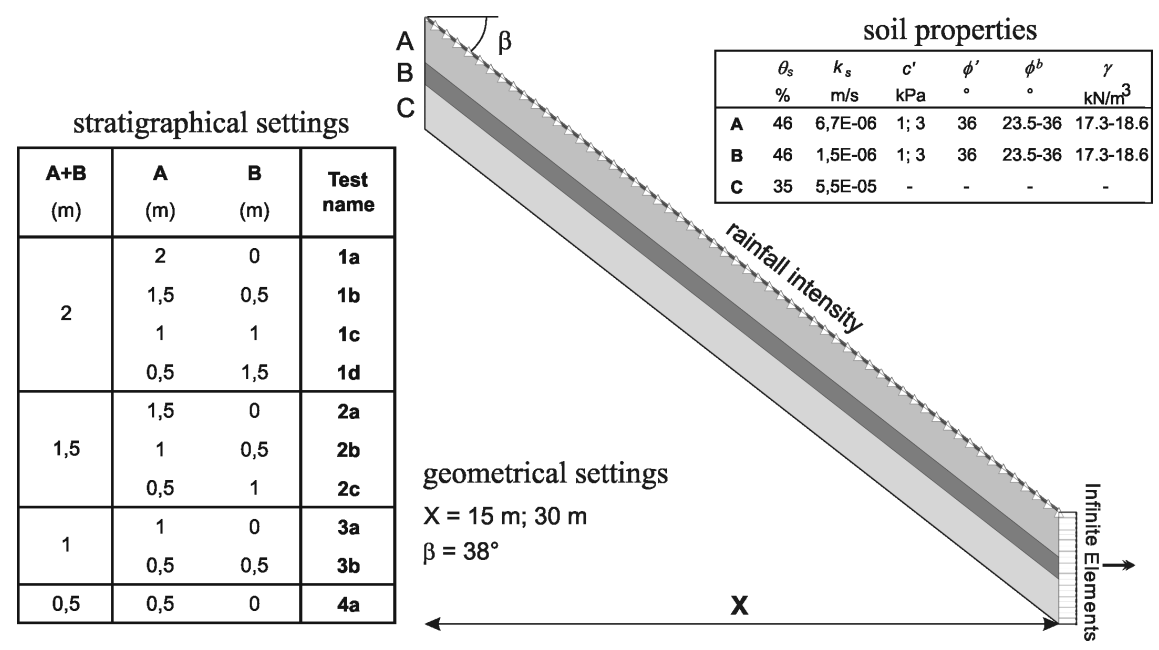

Fig. 2. Stratigraphical and geometrical settings, seepage finite element model and hydraulic and geotechnical parameters adopted in the analyses.

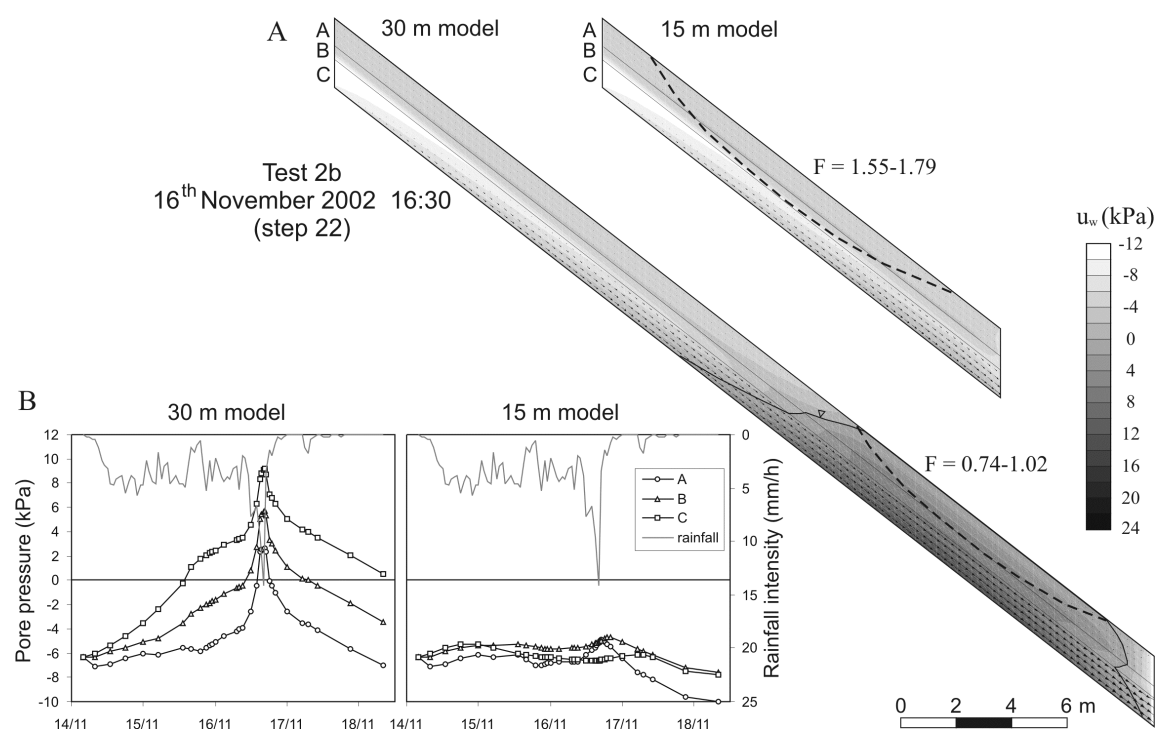

Fig. 3. Test 2b. A) Pore pressure distribution, flux vectors, and critical failure surface at time step 22 (16:30 on 16 November) for $15 \mathrm{~m}$ and $30 \mathrm{~m}$-long models; B) rainfall intensity and pore pressure changes versus time for all the three soils at a horizontal distance of $7.5 \mathrm{~m}$ from the downslope model boundary.

Morgenstern-Price method. The geotechnical parameters adopted for layers A and B are reported in Fig. 2. Two sets of analyses were carried out, assigning two different effective cohesion values ( $1 \mathrm{kPa}$ and $3 \mathrm{kPa}$ ) to the soils, based on results of laboratory and in situ investigations.

\section{Results}

Figure 3 a shows pore water pressure distribution, flux vectors and the most critical failure surface computed for Test $2 \mathrm{~b}$ at time step 22 , corresponding to $16: 30 \mathrm{LT}$ on 16 November, where maximum pore pressures were computed, for both the
$15 \mathrm{~m}$ and $30 \mathrm{~m}$ long models. In Fig. $3 \mathrm{~b}$ the pore pressure for soils A, B and C is plotted versus time for the same models at a horizontal distance of $7.5 \mathrm{~m}$ from the downslope edge of the section. It is interesting to note the different results obtained for the $15 \mathrm{~m}$ and the $30 \mathrm{~m}$ long models. In the shorter section a slight increase in pore water pressures takes place in the upper horizons immediately after the maximum rainfall intensity, followed by a general decrease after the end of rainfall. During the whole simulation computed pore water pressures are always negative. On the contrary, in the lower reach of the $30 \mathrm{~m}$ long model a positive pore pressure pulse is recorded already after the second rainy day (15 November), originating in the lower horizon (C) and progressively 
increasing in thickness. A temporary saturated zone develops and builds up to the surface, originated by the downslope flow parallel to the impermeable boundary at the bottom. The minimum factor of safety (SF) is computed for both models at time step 22 and varies in the range 1.55-1.79 and $0.74-1.02$ for the $15 \mathrm{~m}$ and the $30 \mathrm{~m}$ long sections, respectively, depending on the effective cohesion value adopted in the analysis $(1-3 \mathrm{kPa})$. The computed time of landsliding is in agreement with witness reports for the November 2002 event.

\section{Conclusions}

The triggering mechanisms of the shallow failures that occurred in the Albaredo Valley during the 14-16 November 2002 meteoric event were analysed. The reconstruction of pore water pressure changes within the analysed sections allowed an accurate analysis of slope stability conditions to be accomplished. The analyses demonstrated that slope length is a fundamental parameter for generating pore pressure pulses and so instability conditions. This stresses the importance of upslope flow as well as groundwater convergence. For the analysed event, an effective cohesion of $3 \mathrm{kPa}$ seems to constitute the critical value for the stability of $30 \mathrm{~m}$ long planar slopes.

Edited by: L. Ferraris

Reviewed by: anonymous referees

\section{References}

Aleotti, P.: A warning system for rainfall-induced shallow failures, Engineering Geology, 73, 247-265, 2004.

Aleotti, P. and Polloni, G.: Heavy rain triggered shallow failures in the Albaredo Valley (Italian Central Alps) during the November 14-16, 2002, Geophys. Res. Abstr., 5, 2003.

Amoozegar, A.: Compact constant head permeameter for measuring saturated hydraulic conductivity of the vadose zone, Soil Science Society of American J., 53, 1356-1361, 1989.

Cancelli, A. and Nova, R.: Landslides in soil debris cover triggered by rainstorm in Valtellina, Proc. 4th Int. Conf. and Field Workshop on Landslides, Tokyo, 1, 267-272, 1985.

Ceriani, M., Lauzi, S., and Padovan, N.: Rainfalls and debris flows in the Alpine area of Lombardia Region, Central Alps - Italy, Mem. Soc. Geol. It., 48, 917-921, 1994.

Moser, M. and Hohensinn, F.: Geotechnical aspect of soil slips in Alpine regions, Engineering Geology, 19, 185-211, 1983.

Geo-Slope Int. Ltd.: SEEP/W v.4 user manual, Calgary, Alberta, 1998a.

Geo-Slope Int. Ltd.: SLOPE/W v.4 user manual, Calgary, Alberta, 1998b. 